\title{
Arsenic removal from natural contaminated groundwaters in Calabria Region (Italy) by nanofiltration
}

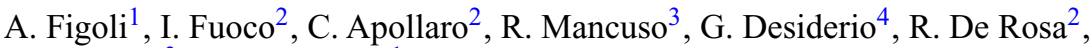 \\ B. Gabriele ${ }^{3} \&$ A. Criscuoli ${ }^{1}$ \\ ${ }^{1}$ Institute on Membrane Technology (ITM-CNR), Rende (CS), Italy \\ ${ }^{2}$ Department of Biology, Ecology and Earth Sciences (DIBEST), University of Calabria, \\ Rende (CS), Italy \\ ${ }^{3}$ LISOC Group, Department of Chemistry and Chemical Technologies, University of Calabria, \\ Rende (CS), Italy \\ ${ }^{4}$ DeltaE, University of Calabria, Rende (CS), Italy
}

\begin{abstract}
Nanofiltration (NF) has been applied for treating arsenic contamination of groundwater from an area located in the Sila Massif in Calabria (Italy). High values of As in different environmental matrices, such as rocks, soils and waters, were observed. In fact, the geochemical analysis of 3 groundwaters (GWs) samples collected show As values which exceeded the permitted levels of $10 \mu \mathrm{gL}^{-1}$. The Arsenic is present mainly in the pentavalent form $(\mathrm{As}(\mathrm{V}))$. Different types of NF membranes, operating conditions and the competing effects of different ions with Arsenic in the GWs samples have been evaluated for analyzing their effect on the arsenic removal.
\end{abstract}

\section{INTRODUCTION}

Arsenic is a toxic inorganic pollutant for both the environment and human health. The removal of arsenic is one of most problematic targets of hydrogeochemical research (Ahmad et al., 2017; Bhattacharya et al., 2002; Mohan and Pittman, 2007; Smedley and Kinniburgh, 2002). The WHO drinking water guideline for As has been set to $10 \mu \mathrm{g} \mathrm{L}^{-1}$ and it has been adopted by many countries as a drinking water standard (WHO, 2001). For reaching this new value, several separation techniques have been studied. Membrane technology is one of these and pressure driven operation as nanofiltration (NF) and reverse osmosis (RO), often applied on synthetic solutions, have been already proved to accomplish the arsenic value below the drinking water standard (Ahmad et al., 2017; Figoli et al., 2016). In this study, NF has been applied for treating As contaminated groundwaters, coming from an area located in the Sila Massif (Calabria, Italy). Sila Mas-sif represents the major morphostructural high of the Ionian margin of northeastern Calabria and fall in the northern sector of the Calabrian Peloritan Arc (CPA). The water samples collected, labeled GW1, GW2, GW3, have interacted with the Calabride Complex formed by Hercynian and pre-Hercynian gneiss, granite and phyllite, which underwent intense weathering processes (Van Dijk et al., 2002). The performance (water flux and arsenic rejection) of the membranes has been evaluated changing the operating pressures.

\section{METHODS}

The three water samples (GW1, GW2, GW3) differ by the arsenic concentration, which is about 60,120 and $430 \mu \mathrm{g} \mathrm{L}^{-1}$, respectively. The arsenic is present mainly in the pentavalent form $(\mathrm{As}(\mathrm{V}))$.

NF experiments were performed by using a laboratory pilot unit (SEPA CF), consisting of three major components: a cell body, cell holder, and feed pump. Four types of membrane modules commercialized by GE Osmonics, named HL (polyamide), DK (proprietary thin-film) and CK (cellulose acetate) and by Microdyn Nadir, named NP030P (polyethersulfone), were used.

The samples, before and after membrane treatment, have been analyzed, determining the major elements HPLC (Dionex ICS 1100). The total arsenic was evaluated by ICP-MS, Perkin Elmer/SCIEX, Elan DRCe.

\section{RESULTS AND DISCUSSION}

In Figure 1, it is reported the water flux plotted versus the trans-membrane pressure (TMP) variation, for the GW2 sample (feed stream).

All the investigated membranes show a linear increase of water flux at higher TMP. In particular, only the NF membrane Type HL shows much higher water flux compared to the other ones, which could be 


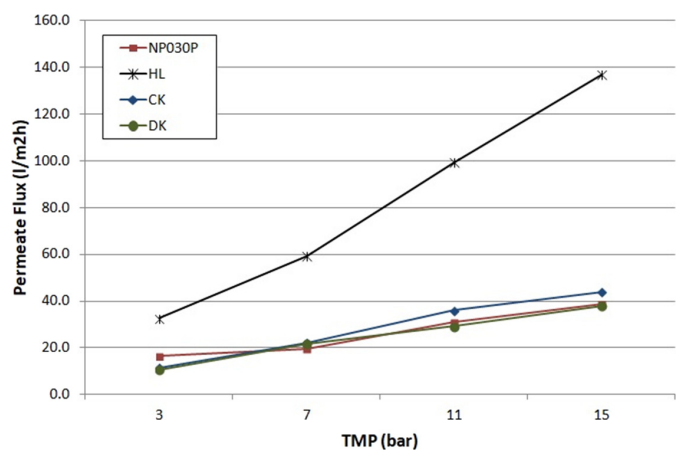

Figure 1. Effect of TMP on permeate flux for GW2 contaminated As(V) sample.

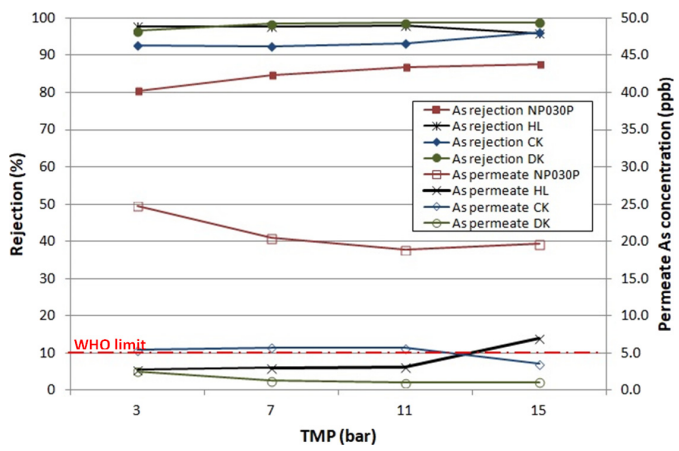

Figure 2. Effect of TMP on rejection (\%) and permeate arsenic concentration for GW2 contaminated As(V) sample.

explained by the polymeric nature of the material as well as by its higher pore-size. The same results have obtained also for the other GW samples containing a lower and higher concentration of $\mathrm{As}(\mathrm{V})$.

In Figure 2, it is reported the $\mathrm{As}(\mathrm{V})$ rejection and the arsenic concentration detected in the permeate (purified water) after the membrane treatment of GW2 contaminated As (V) sample.

The results show that all the investigated NF membranes, except the NP030P, reject the As(V) and that the $\mathrm{As}(\mathrm{V})$ concentration in the purified permeate water is below the WHO drinking water limit value of $10 \mu \mathrm{g} \mathrm{L}^{-1}$.

\section{CONCLUSIONS}

The results clearly report that NF can be considered a valid technique for arsenic removal in the natural water, producing a permeate (purified water) with the $\mathrm{As}(\mathrm{V})$ concentrations within the allowed WHO limits for most of the membrane investigated.

\section{ACKNOWLEDGMENT}

The work has been supported by the project "AsSe" n. CUP: J28I17000030006, cofunded by Fondo FESR POR Calabria FESR FSE 2014-2020-Azione 1.2.2.

\section{REFERENCES}

Ahmad, A., Richards, L.A. \& Bhattacharya, P. 2017. Arsenic remediation of drinking water: an overview. In: P. Bhattacharya, D.A. Polya \& D. Jovanovic (eds) Best Practice Guide on the Control of Arsenic in Drinking Water. Metals and Related Substances in Drinking Water Series. IWA Publishing, UK, pp. 79-98.

Bhattacharya, P., Frisbie, S.H., Smith, E., Naidu, R., Jacks, G. \& Sarkar, B. 2002. Arsenic in the environment: a Global perspective. In: B. Sarkar (ed) Handbook of Heavy Metals in the Environment, Marcell Dekker Inc., New York, pp. 147-215.

Figoli, A., Hoinkis, J. \& Bundschuh, J. 2016. Membrane Technology for Water Treatment, Removal of Toxic Trace Elements with Emphasis on Arsenic, Fluoride and Uranium. CRC Press, Boca Raton, FL.

Mohan, D. \& Pittman, C.U. Jr. 2007. Arsenic removal from water/wastewater using adsorbents - a critical review. $J$. Hazard. Mater. 142(1-2): 1-53.

Smedley, P.L. \& Kinniburgh, D.G. 2002. A review of the source, behaviour and distribution of arsenic in natural. waters. Appl. Geochem. 17(5): 517-568.

Van Dijk, J.P., Bello, M., Brancaleoni, G.P., Cantarella, G., Costa, V., Frixa, A., Golfetto, F., Merlini, S., Riva, M., Torricelli, S., Toscano, C. \& Zerilli, A. 2000. A regional structural model for the northern sector of the Calabrian Arc (southern Italy). Tectonophysics 324: 267-320.

WHO 2001. Guideline for drinking-water quality: arsenic in drinking water. Fact Sheet No. 210. World Health Organization, Geneva. Switzerland. 